\title{
HealthTEC Innovation Design - a proposal for a novel Master degree program based on Unmet Clinical Need, global Healthcare Challenges, and 21 st century skills
}

\author{
Michael H. Friebe *a, b
}

\begin{abstract}
The effectiveness, efficiency, availability, agility, and equality of global healthcare systems are in question. The COVID-19 pandemic have further highlighted some of these issues and also shown that healthcare provision is in many parts of the world paternalistic, nimble, and often governed too extensively by revenue and profit motivations. The 4th industrial revolution - the machine learning age - with data gathering, analysis, optimisation, and delivery changes has not yet reached Healthcare / Health provision. We are still treating patients when they are sick rather then to use advanced sensors, data analytics, machine learning, genetic information, and other exponential technologies to prevent people from becoming patients or to help and support a clinicians decision. We are trying to optimise and improve traditional medicine (incremental innovation) rather than to use technologies to find new medical and clinical approaches (disruptive innovation). Education of future stakeholders from the clinical and from the technology side has not been updated to Health 4.0 demands and the needed 21 st century skills. This paper presents a novel proposal for a university and innovation lab based interdisciplinary Master education of HealthTEC innovation designers.
\end{abstract}

Keywords: Healthcare Innovation, Biodesign, Exponential Technologies, Prevention, Health 4.0, Biomedical Entrepreneurship, Healthcare Ethics, Biomedicalengineering Education, Healthtec Innovation Management, 21st century skills, Health Democratization, Reverse Innovation

https://doi.org/10.1515/cdbme-2020-3153

*Corresponding author: Prof. Michael Friebe, PhD

a) INKA - Application Driven Research, Faculty of Medicine, Otto-von-Guericke University, Magdeburg, Germany, e-mail: michael.friebe@ovgu.de, http://www.inka-md.de

b) IDTM GmbH, Recklinghausen, Germany, http://www.friebelab.org

\section{Introduction}

There are significant challenges in present and future global healthcare delivery. Some countries have abundant services, but are stuck with a rather nimble and expensive system that focuses on incremental innovations. Other geographies are still in need of basic systems, educated staff, health infrastructure, and require completely different, inexpensive, and with that more disruptive solutions.

Healthcare 4.0 with a focus on prevention / early detection and pro-active therapy will employ exponential technologies (AI, Big Data, Sensor Technology, Synthetic Biology, Robotics, 3D Printing, ...) that will surely lead to significant changes in the way we experience and deliver healthcare where an empowered patient will play a more and more important role. [1-3]

In the coming years/decades we will experience a shift from SICKCARE to HEALTHCARE to HEALTH, with more of the health related monitoring and evaluation done in a homecare setting and a much larger focus on prevention (including physical exercise, food, mental health training, and many more) made possible by the upcoming technology developments. This will also lead to a reorganisation of healthcare delivery and workflows. We will not only deal with and handle Product Innovations, but will see significant Business Model Innovations and subsequently a Health Industry Transformation.

Health innovation needs to be based on meaningful solutions that actually solve an identified and meaningful problem, that can also include availability, excessive cost, or difficult handling. These problems can be regionally different based on the delivery setup and can also be based on issues related to inequalities as shown in diagnostic and treatment availabilities and available funds to pay for these services. Health related problems need to be identified taking future potential of technology developments into consideration including future 


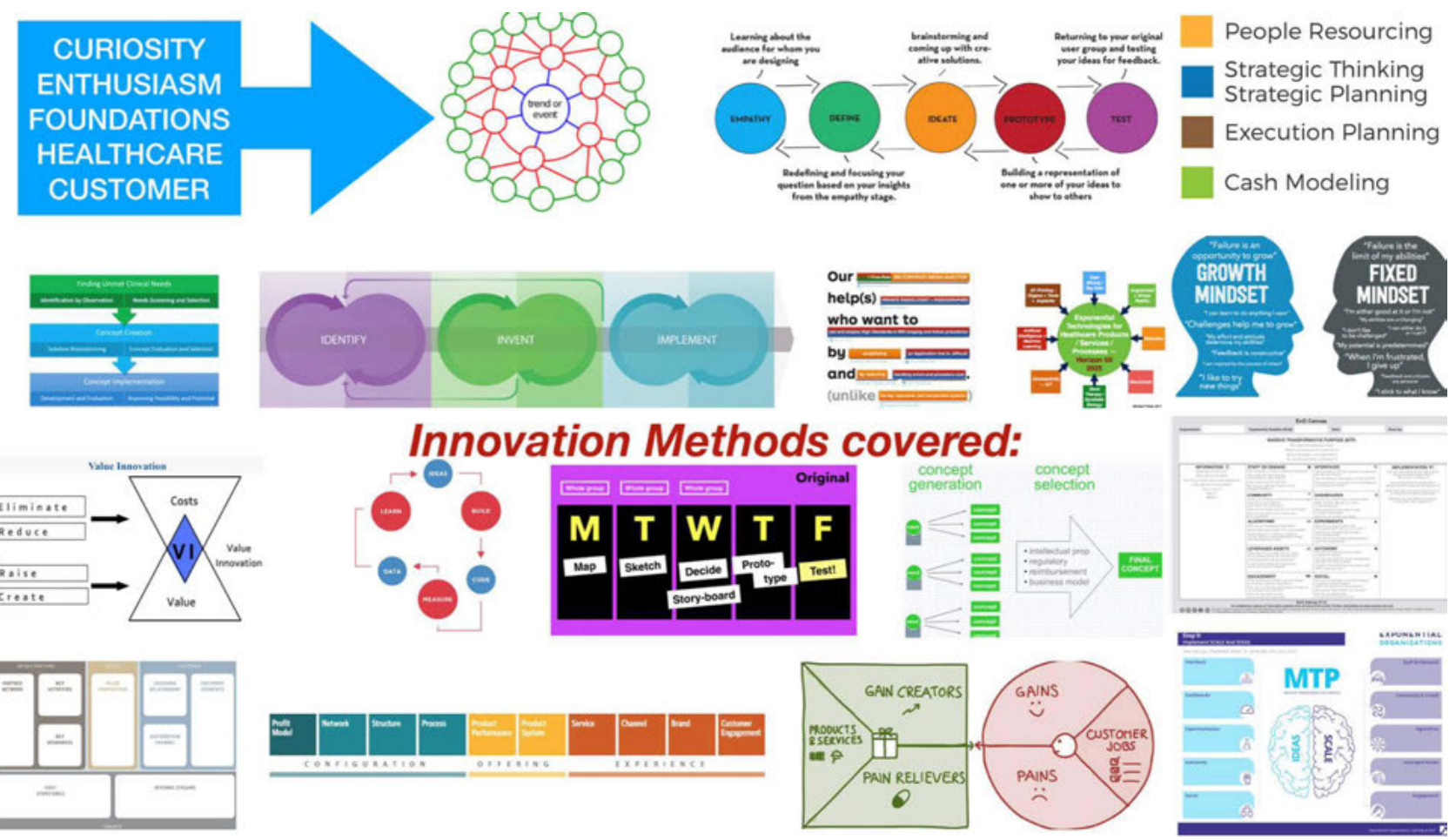

economics and delivery changes.

Which leads to the question on whether we actually teach our biomedical engineering students the right skills considering these foreseeable future developments.

Is it necessary for someone that is trying to identify and subsequently looking for applied innovation potential in the health delivery field to be a deeply trained data scientist, or robotics engineer, or machine learning expert? - Answer: No.

But, to be a good health innovator is it possibly enough to know the potentials and impact of these technologies and apply them to healthcare needs and economic realities? Answer: Yes. [4-6]

Globally, healthcare of the future will require 4 value propositions that should be fulfilled after the development:

\section{Improve Patient and}

2. Clinical Staff experience,

3. Improve the outcome (reduce diagnosis and treatment errors and pick the therapy with the most value for the individual), and

4. dramatically reduce associated cost.

One way to achieve that is to move healthcare delivery from acute care to ambulatory care and from ambulatory care to home- or self care with a focus on maintaining ones health and help the individual to prevent from getting sick. This requires trusted and connected advanced sensorics and machine-/ deep learning for monitoring health conditions and comparing the results to peers and to the own individual historic data set. But it also requires a sound clinical understanding and knowledge on innovation generation techniques, as well as on the health economic environment, which are significantly different looking at it from a global perspective.

In the context of these anticipated changes different skill sets are required for future health innovators than currently taught. The innovators need to have an understanding of the possibilities of exponential technologies in the health context, be empathetic with respect to the clinical stakeholders and the patients, be able to identify problem areas, and to setup, manage, and work within interdisciplinary teams (clinical, engineering, science, economics, design) on feasible solutions that can be translated in form of an entrepreneurial venture, open access or with industry in a licensing agreement.

We are currently still educating and training in silos: the clinician with little to no technology awareness training, the engineer with little to no training on clinical workflow and associated needs, the economist with a focus on numbers rather than a focus on understanding the patient - clinician interaction, and none of them on how to work in teams and on 
how to innovate, develop based on needs, and translate into clinical practice.

Such an interdisciplinary educational setup covering technical, science, economics, and clinical disciplines (in a university represented by faculties) is most likely a difficult and frustrating undertaking considering the relatively slow and nimble processes of making decisions in universities and with respect to changing teaching curricula.

\section{Methodology}

With all these upcoming changes and challenges we should introduce a "HealthTEC Innovation Design - HTID“" Master of Research program that embraces technological developments, understands the needs of future healthcare (reducing cost, improving patient and clinician experience, reducing medical errors and improving outcomes), teaches entrepreneurial basics and exponential thinking in an interdisciplinary setting with the ultimate goal to help democratize and personalize healthcare and put the patient in the center of our activities. [7,8]

A very feasible and valuable example of a MRes program was successfully introduced by Imperial College (MRes Medical Device Design and Entrepreneurship [9]) covering some core teaching modules (Computational and Statistical Methods for Research, Medical Device Entrepreneurship, Topics in Biomedical Engineering and Business), combined with innovation and team exercises, and otherwise focussing on conducting a relevant and innovative research project based on an identified UNMET CLINICAL NEED.

This newly proposed HTID-MRes should consist of academic teaching on Global Health Economics, Biodesign based Innovation Generation, Exponential Healthcare Technologies, Intellectual Property, HealthTEC Start-Up Basics, Exponential Organisation Attributes and Scaling-Up Techniques, Problem-Solving / Empathy / Ethics, Scientific Writing, and other innovation lectures (see Figure 1 for a summary of the covered Innovation Methods).

The teaching should consists of a total of 450 hours (e.g. 30 weeks of 12 academic hours plus a 3 week summer school with 90 academic hours) plus two academic projects (small research team project with 15 ECTS and a Master thesis with 30 ECTS). The academic program with exception of the summer school could also be offered as blended learning or exclusively virtually online. The Master Thesis research topic could then also be used by the medical students as a part or complete fulfillment of their MD medical thesis.

The ideal candidate would be a (student) scientist / engineer / health economist (Bachelor degree as minimum entry requirement), Medical Student (completed 4th year and willingness to take a year off from medical studies) that wants to understand real innovation and future oriented thinking in the healthcare domain and what $\mathrm{AI}$ and other exponential technologies will allow us to do and will force us to implement.

\section{Discussion and Conclusion}

To move HEALTHCARE from the current SICKCARE to actual HEALTH provision and maintenance we need dedicated Innovators, people that liaise between the technology development, the clinical users / needs, and the patient. Innovators that are able to identify problem areas, are able to look for disruptive solutions, put a team together and iterate the results for maximum impact.

This Innovator could be an engineer that has the right skill set and empathy / understanding to the clinical problems, a clinician that is interested in learning about the possibilities of new technologies, or an economist that is willing to learn the technological capabilities within a clinical / patient entered environment. Or ideally could be an interdisciplinary innovation team.

This proposed HTID-MRes could provide the training and soft skills to innovate for a global market by focussing on solving unmet clinical needs through observation of the clinical processes and with the knowledge of future technological developments (IDENTIFY), followed by application of innovation generation tools (INVENT), and an iterative reevaluation (going back to the stakeholders to confirm the findings and verify the ideas) within economic realities and a subsequent IMPLEMENTATION.

Two additional skill are often neglected during the university based education, but equally if not more important. LIFE SKILLS (curiosity, taking initiative, leadership, social awareness and ethical and moral responsibility) and LEARNING SKILLS that consist of the ability to critically think, to work in collaborative and interdisciplinary teams, and to communicate. [10]

Both of these are important pillars of the proposed HTIDMRes program.

Health innovation (defined as Invention $\mathrm{x}$ Commercialization) rarely comes from just one technology segment, but often when several domain expertise come together (e.g. electronics to develop the sensors, mechanical and material engineering to develop biocompatible components, signal processing expertise to prepare the data, computer science to establish 
https://hbr.org/2000/09/will-disruptiveinnovations-cure-

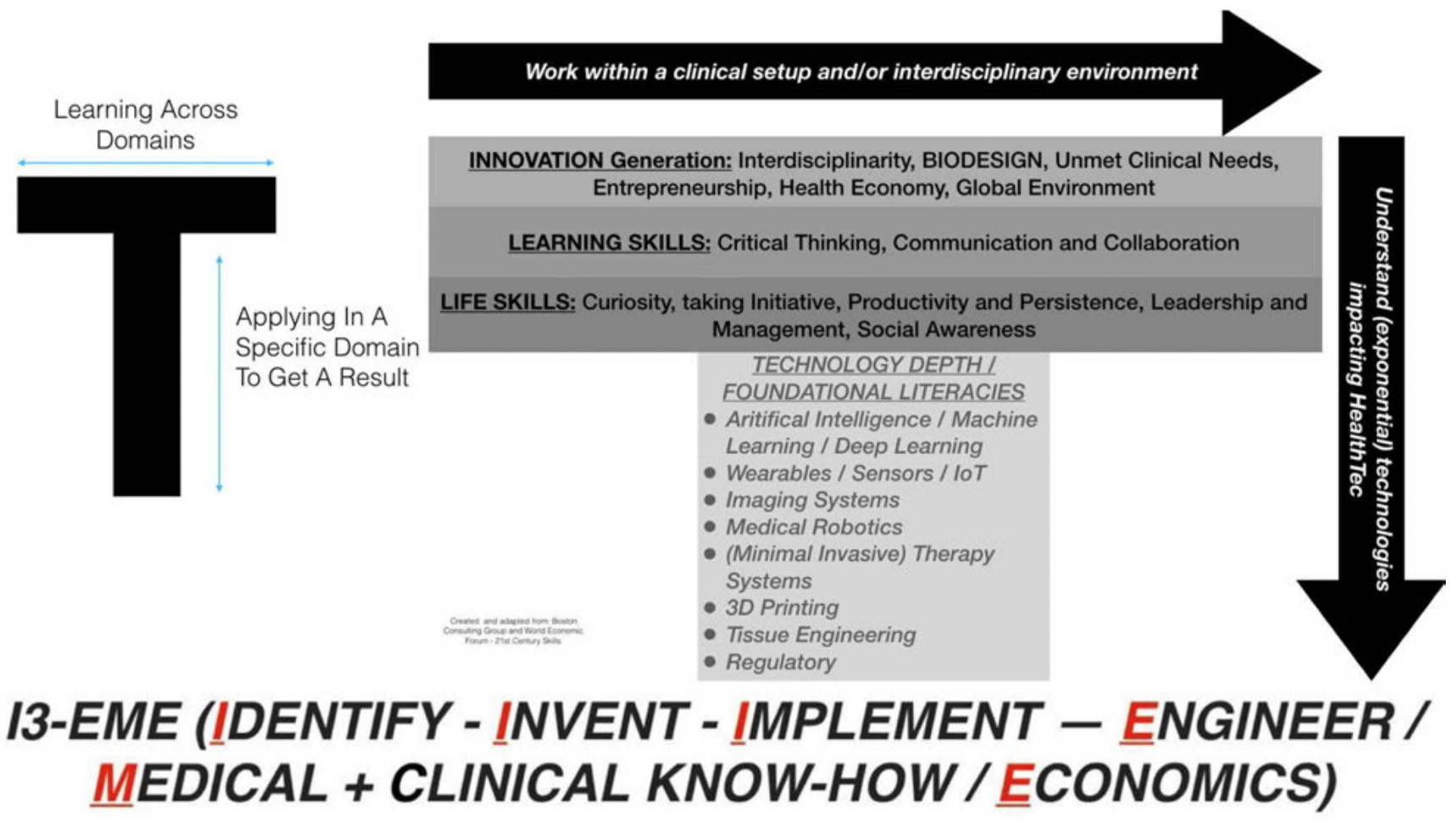

user interface and artificial intelligence). But this still does not lead to a future implementation, if the technology innovator does not understand the clinical users, or the patient needs, and is ignorant about the associated health economics.

This is why the HTID-MRes should cover future technologies and their capabilities for health applications, basics on economics, teaching relevant soft skills and entrepreneurship plus a solid understanding of the current clinical processes with respect to the anticipated upcoming healthcare changes.

The HTID-MRes has the potential to educate future health innovators that follow the I3-EME formula, of IDENTIFYING clinical problems, INVENT / IDEATE solutions, iterate them and subsequently IMPLEMENT them by using the expertise of Engineers, Medical stakeholders, and Economists (see Figure 2). [11]

\section{References}

[1] Hendricks, D., "Why Entrepreneurs Are the Future of Healthcare.". $\quad$ http://www.inc.com/drewhendricks/whyentrepreneurs-are-the-futureofhealthcare.html (2016).

[2] Christensen, C., Bohmer, R., Kenagy, J., "Will Disruptive Innovations Cure Health Care?", HARVARD BUSINESS REVIEW, Sept-Oct 2000 issue, DOI:

health-care (2000).

[3] Dhavan, A., et al, "Current and Future Challenges in Point-ofCare Technologies: A Paradigm-Shift in Affordable Global Healthcare with Personalized and Preventive Medicine.", IEEE Journal of Translational Engineering in Health and Medicine 2015 Mar 5;3:2800110 (2015).

[4] Christensen, C., Waldeck, A., Fogg, R., "The Innovation Health Care Really Needs: Help People Manage Their Own Health.", Harvard Business Review Oct. 30, 2017, https://hbr.org/2017/10/the-innovation-health-care-reallyneeds-help-people-manage-their-ownhealth?autocomplete=true (2017).

[5] Friebe, M., [International Healthcare Vision 2037. New Technologies, Educational Goals and Entrepreneurial Challenges], Otto-von-Guericke-Universität, Magdeburg, ISBN: 978-3-944722-59-7 (2017).

[6] Friebe, M., "Exponential Technologies + Reverse Innovation = Solution for Future Healthcare Issues? What Does It Mean for University Education and Entrepreneurial Opportunities?", Open Journal of Business and Management, 5, 458-469, DOI: https://doi.org/10.4236/ojbm.2017.53039 (2017).

[7] Friebe, M, "Healthcare Translation and Entrepreneurial Training in and for Egypt -- Case Study and Potential Impact Analysis. ", Open Journal of Business and Management, 5: 51--62, DOI: https://doi.org/10.4236/ojbm.2017.51005 (2017).

[8] Friebe, M. and Traub, J., "Image guided surgery innovation with graduate students - a new lecture format.", Current Directions in Biomedical Engineering 09/2015; 1(1), DOI: https://doi.org/10.1515/cdbme-2015-0114 (2015).

[9] Moore J., MRes Medical Device Design and Entrepreneurship. Imperial College, London. https://www.imperial.ac.uk/study/pg/bioengineering/medicaldevice-design-mres/ 
[10] Bailey, A., Kauffman, B., Subotic, S., "Education Technology and the 21st-Century Skills Gap.". https://www.bcg.com/publications/2015/public-sectoreducation-technology-21st-century-skill-gap.aspx (2015).

[11] Friebe M., "Healthcare in need of innovation: exponential technology and biomedical entrepreneurship as solution providers.", Proc. SPIE 11315, Medical Imaging 2020: ImageGuided Procedures, Robotic Interventions, and Modeling, DOI: https://doi.org/10.1117/12.2556776 (2020). 